\title{
SOCIAL MEDIA USER BEHAVIOR AND IMPLICATIONS BASED ON SOCIAL- APPLIED PSYCHOLOGY PERSPECTIVE
}

\author{
Mulawarman Mulawarman \\ Department Guidance and Counseling \\ Faculty of Education, Universitas Negeri Semarang \\ Semarang, Indonesia \\ mulawarman@mail.unnes.ac.id
}

\author{
Aldila Dyas Nurfitri \\ Faculty of Psychology \\ Universitas Katolik Soegijapranata \\ Semarang, Indonesia
}

\begin{abstract}
Social media becomes a new tool for many areas to perform functions and works, such as political campaign media, advertising, and teaching. However, the use of social media nowadays also raises excessive effects which could be serious problems if it was not overcame as soon as possible. There are some social media use behaviors that should be observed, such as selfie, cyber war, online shopping, user-personalization, and shared-culture. Through the study of social psychology, it is expected that readers have more comprehensive perspective in looking at the phenomenon of social media hegemony as part of contemporary social reality.
\end{abstract}

Keywords: social media, selfie, cyber war, online shopping, user-personalization, shared-culture

\section{INTRODUCTION}

Nowadays, it is almost certainly that everyone who has smartphone also has a social media (even more) account, such as Facebook, Twitter, Path, Instagram, and so on. It has been common that changes communication way in the digital era currently. The evolution occurred in the field of technology and internet innovation led to not only bring new media. Various aspects of human being, such as communication and interaction, also changes that were never expected. The world seems have no limits (borderless) - no secrecy can be covered. We know people activity through social media, while we do not know and never meet in person.

Social media becomes "new weapon" for many fields. Political campaigns on 2014 involves much of social media roles. Companies put their attention to managing social media and establishing good relationships with their online customers (in the network). Advertisement has been changed from traditional way which is followed with high cost producing. It is a challenge as well as a reality that cannot be denied. The presence of social media and the growing number of users day by day provides an interesting fact how the power of the internet for life [1].

Research were conducted by Crowdtap, Ipsos MediaCT, and The Wall Street Journal in 2014 involves 839 respondents with the range number of age of 16 to 36 years old shows that the respondents spent their time to access internet and social media is 6 hours 46 minutes each day is higher than accessing traditional media [1]. In other sentence, it could be conclude that traditional media is no longer being dominant medium accessed. People need to establish their social relationship is the main reason why most people using social media as daily media. This condition cannot be obtained when they are accessing traditional media.

Cyberspace as well as social media is a great revolution that changes human behavior, where all friendship relationship is done through "digitalization" using new media (internet) run through social networking sites. This added reality must be adaptable and integrated within the scope of social psychology studies everywhere and pervasive (can penetrate various fields of science and study) [2]

\section{DISCUSSION}

The term of social media is composed from two words, namely "media" and "social". "Media" is defined as a means of communication [3] [4].While the word "social" is defined as a social reality which individual's action contributes to society. This statement confirms that in fact, the media and all software are "social" or in the sense they are product of social processes [5].

From the above explanation, it can be concluded that social media is a communication tool used by users in social processes. However, to draw up the definition of social media, we need to look at the development of individual relationships with media tools [1]. Characteristics of computer work in Web 1.0 based on the introduction of individuals to other individuals (human cognition) residing in a network system, while Web 2.0 based on human communication in the interpersonal network [1]. Finally, in Web 3.0 the technological characteristics and relationships are evident from how humans (co-operation) work [6].

Thus, it can be explained that the form of social media is basically not rather different from the existence and workings of computers. Three forms of social, such as recognition, communication, and cooperation can be analogous to the workings of computers which also forms a system like a system between individual and society [1].

Presently, online activities conducted by users around the world are fairly massive and intensive. There are many motives and goals that underlie users in accessing online services, especially social media. We will present 
some analysis of the most recent content issues relating to the social media use which are considerable interest to academics and researchers.

\section{Social Media and Recent Issues Selfie}

One of the phenomena in the advancement of internet technology and cyber culture is selfie. This word has also officially become a new word written in the Oxford English Dictionary dictionary in 2013 and simply means 'self-image disseminated through social media' [1]. According to Saltz, selfie as an instant self-portrait, created with a smartphone camera and immediately disseminated or transformed over the internet as a form of instant visual communication about where we are, what we do, what we think, and who would see the photo [1].

Historically, self-images appear and can be viewed in unison with the presence of photography tools on mobile phones. Unlike digital photos using DSLR or other prosumer, using a mobile phone, photos taken can be directly uploaded on social media right away. This reality brings up a novel in, users want to share their moments or activities with other friends on social media networks. Further reality, by uploading selfie in own social media aims to the exsistence of uploader and showing off what they have achieved so far. Therefore, a selfie photo cannot be judged just from the facial, expression and style. Analysis of selfie photo should involve other points, such as context, moment, building, place or environment that becomes an image of ourselves [1].

A research conducted by the Opinium Institute in the UK involves 2005 respondents with the range number of age about 18 to 24 years in 2013 showed that there were over a million self-made photos each day. This social reality of cyber shows that the power of self-images is a cultural artefact that can be interpreted from different points of view. Social media is an arena for displaying photos of themselves and users get reciprocity from the publication [1].

There are several reviews that can be presented in this study related to the phenomenon of doing selfie using the perspective of social psychology. First, the activity as a form of self-existence. Doing selfie and spread it on social media is not just focused on the user's self-appearance. Selfie is an effort of self-representation in social media, an attempt to be considered exist in the network. Someone who does selfie is also trying to construct his social identity by maximizing or minimizing the positive or negative their character to maintain its self-esteem [7].

A hype selfie photo is marked by numerous compliments, 'thumbs up' or 'likes' (featured in Facebook) or 'heart' (featured in Path) then individual could feel satisfied and more compelled re-doing selfie and upload it in social media. However, when the condition is reversed, the individual may feel ignored and unappreciated by his social environment. The situation could be trigger as desire not to re-uploading their selfie photo or still doing it, but with a certain evaluation.

Second, selfie is a form of digital narcissism [1]. Taken selfie indicates that users are designing themselves and as the result, in addition to self-existence, as well as performing in front of people or other social media users to impress them [7].

A selfie photo also must be viewed from the background of the photograph object. Many photos of themselves with the background of a particular location and it shows that user is in that place. On another occasion, a selfie in a public transportation, such an airplane, is to show they were on it. Uploading selfie becomes a symbol that users are realizing their existence that is not just as a photo object, but there is a certain intention on.

Third, selfie can also indicate that users do selfdisclosure in social media. In Lewin's postulation [8], the living field of an organism is like a spider web consisting of several regions. These areas may progressively increase or be static, both in number and extent, depending on the nature of the organism, whether disclosed or closed. Selfie as a growth media of one's living area because it leads them to be open to share photos of themselves in front of followers through their social media accounts.

The further effect of self-disclosure is the interaction and communication with other users will be closer. Even in some cases, uploading selfie photos leads increasing new friendships, resulting wider social networking, or in other words, the area of one's life will be more spacious.

\section{Cyberwar}

Did you remember the phenomenon of fanaticism supporters of Jokowi and Prabowo in contesting 2014 election back then? Both of groups competed each other before the election was held until several months later.

The atmosphere of zeal to rowdy caused by opinions or news related to the figure of Jokowi or Prabowo becomes an inevitable color. There are many Jokowi stereotypes used as 'weapons' by Prabowo's supporters, such pro-communist, pro-Shia, and nasab obscurity (family lineage). And vice versa, Prabowo's stereotype which is often used as 'weapon' by the Jokowi camp is a number of human rights violation cases.

Stereotypes becomes basic material of belief in individuals and groups (collectively), and in certain situations, beliefs becomes prejudices that can further ignite discriminatory or other noncooperative behaviors, such as slander and group hostility [9].

According to some experts, collective behavior is defined as an action taken jointly or simultaneously in a manner similar to a large number of people in group of particular situation or event, which can be unusual actions [10] [11].

The behavior embodiment of Jokowi and Prabowo supporter groups uniquely occurs massively in the online environment or struggling in the constellation of social media collected in certain communities. Unreasonable 
debate and hoax wars seems to be usual feed in our social media stream, besides news or supporting status for them.

There are several determinants of collective behavior, such as structural conduciveness, which is a factor of social situation structure that facilitates collective behavior, such as religious, ethnic, ideological, and racial diversity in a region; structural strains, namely disparities, incompatibility between social groups, ethnic, religious, and others that provide opportunities for various forms of tension [10]. The greater of structural tension, the greater of collective behavior chance; general belief, which is a very trustworthy rumor and then disseminated; precipitating factor, which is a factor supporting the suspicion and anxiety conceived by society; mobilization of participants, the embodiment of collective behavior led by the leadership, either to move away from dangerous situations or to approach people who are considered targets of action.

Group membership is considered to increase the effectiveness of individual action, within the group of individuals who belong to the group will change the way they behave according to the norms applicable in the group [10]. Individuals in a row of masses, regardless of work, characteristics, intelligence, or other attributes, will react directed by a collective mind or group mind [12].

They will react to group thinking and produce behaviors that are different from the behaviors when they are separated from the group. The contagion effect will spread the emotions and behavior causing individuals in a mass to react in the same way.

Related to the behavior of Jokowi and Prabowo supporters, a particular set of social media users initially exhibits turmoil and reaction with a process called milling, a process which individuals become increasingly tense, anxious, and excited [12]. By increased emotion, excitement and mutual stimulation, people are more likely to act impulsively under the influence of shared impulses called collective mind or group mind.

If the intensity of this process increases, then social contagion will arise involving rapidly impulses dissemination or or conscience [12]. These social transmission often causes social media users becomes more active in behaving together, though in online situation.

Furthermore, the shared enthusiasm in the collection of users may involve circular reaction processes (circular reactions) [12]. Thus, when a person becomes anxious, restless or excited, then the emotion and behavior will become a model that is transacting others. This mutual stimulating process produces a spiral of circular feelings and actions

\section{Online Shopping}

Shopping lifestyle in Indonesia is always changing over time, especially electronic shopping trends adapted to various social media, ranging from the attractiveness of banner ads, video tutorials, discounts, payments through joint accounts to the system after payment received (Cash On Delivery). The company's success to utilize e commerce in marketing its products is followed by the irony of blurring reality in the community — spending on the needs or form of an impulsivity.

Social networking sites like Facebook that initially only serve as a site of friendship and exchange of information among friends or close relatives, has now switched function as a marketing ground of a company or online store in the scale of home industry. Not just social networking sites like Facebook. Other online media such as forums, blogs and micro-blogs such as Twitter can be a place to conduct e-commerce activities in cyberspace.

For consumers, online shopping will be very high if they are satisfied with the quality of services from the online sales system on the site. Customer satisfaction while shopping online and customer satisfaction after making a purchase into an indicator where an online store site can retain its customers by increasing interest to shop back to the site [13].

One of the main goals of marketing strategy is to change consumer attitudes toward a product through a process of persuasion. In many theories of social psychology about attitude, it is explained that there is a very close relationship between attitudes and behavior. Based on the theory of social psychology that supports the close relationship between attitudes and behavior when applied to consumer behavior it can be concluded that if a person's attitude is positive to a product, then the person will buy it. Changing consumer attitudes so they buy or consume a product can be done through a process of persuasion. Persuasion is the conversion of one's beliefs and attitudes toward an object in a certain direction desired by the persuasionist [14].

The information processing model is an approach that explains that the learning process influences one's attitude through a process of persuasion [15]. According to this approach, in order for consumers to buy a product, then there is a learning process passed. The learning process is as follows: interested, understanding, and believe the claims contained in an ad. This learning process will make it easier for them to experience a change in attitude that culminates in the behavior of buying an advertised product. It happens because the result of the process is stored in a person's memory of a certain message which can be used as a basis for processing perceptions, attitudes, and behaviors associated with the existence of a product.

To promote business products online, many companies are competing to make advertising as attractive as possible. Not only advertisement product are attempted to attract the audience, promotional expansion through various social media is also done, such as Facebook, Instagram, Twitter, Snapchat, and others. Even as a marketing strategy also picking up a number of famous names to review the products as they offer. In other words, the more interesting, unique, and widespread the marketing of the product, the easier it is to remember, recognize, and will be bought.

\section{User Personalisation}

The widespread use of Twitter and Facebook has provided a new approach to social science research. It 
requires certain techniques to analyze and interpret data using computer science methods. This technique allows researchers to be able to generate insights from large-scale data sets. The words used on Facebook were a surprisingly reliable personality indicator [16]. The researchers used a language prediction algorithm to make efficient, large-scale personality assessments. Automatic language-based model of the nature, showing results consistent with self-reported personality measurement of participants.

Certain phrases can predict certain personality traits [16]. For example, people who has high score in neuroticism on self-reported are more likely to use words, such as sadness, loneliness, fear and pain. Analyzing this data may provide new connections that may not be visible in traditional written questionnaires and surveys.

In addition, researchers also found that there are many similarities throughout the country, in the form of emoticons associated with positive emotions and curse words, as well as aggression associated with negative emotions [16]. There are also differences that lead to a special cultural correlation for emotional expression.

The social media phenomenon which also attracts the author's attention is the rampant user accounts that deliberately install profile photos instead of him, without profile photos, and without a clear identity [1]. In addition to unidentifiable user accounts, the irony of social media users' behavior is also reflected their attempts to reconstruct an identity through a specific status tag or distribution of a page's link just to 'explain' to users about who and how or just the opposite: not represent user identity at all.

\section{Culture Shared}

Lately appeared pages and blogs are not credible. They do not hesitate to use provocative attributes, such as the word of "spread it" or similar bombastic words. Frequently used messages are "share to another, share, or save". Sometimes accompanied by threats such as chain letters in the past [1].

The phenomenon of the culminating share of culture during the 2014 presidential election. Some prominent figures support certain candidates with or unintentionally twisting the news, commenting on and dropping their political opponents. This is also done by partisan media.

Patterns of hoax coverage are relatively always the same: make a bombastic title to attract reading interest [1]. Sometimes between title and news content is out of sync. Unfortunately, many social media users in this country are lazy to read. They tend to be easily provoked by titles that look interesting and instantly share certain page links without reviewing it at first.

The reality of Indonesian society, even today's world seems interesting to be seen from the perspective of social cognition. Social cognition is defined as the workings of the human mind to understand the environment so that humans can function in it adaptively [9]. The workings of this mind include the activities of interpreting, analyzing, remembering, and using information about the social world.
A scheme is a basic component of social cognition defined as a mental framework or structure that helps people organize social information and guide its processing [9]. Schemes revolve around a particular subject or theme and the scheme is shaped by the culture in which we live.

Schemes have a powerful effect on three basic processes: attention, encoding, and retrieval [9]. In relation to attention, the scheme acts as a filter: information that is consistent with the schema is more concerned with processing in human consciousness, while inappropriate information is often ignored unless the information is so extreme that we are unwilling to pay attention to it, such as the strategy used in hoaxes by using bombastic headlines. Consciously or not, the information received by users of social media while digesting the hoax news encourages for similar news-feeding because their mental schemes are congruent for a particular theme or preference.

\section{CONCLUSION}

The hegemony of social media can be seen through the perspective of social psychology (applied), including the concepts, theories and the results of social psychology research in the behavior of individuals related to topics related to social media use activities such as selfie, cyberwar, online shopping, personal user-personalisation, and culture shared. Human behavior which is increasingly inseparable from the (reality) of the virtual world should be a serious concern, so in each sub-theme of social media behavior as mentioned above can be followed up as a research idea for enthusiasts of social psychology studies in particular, related disciplines and expected from the research results of each sub-theme obtained specific results and discussions that enrich the study of the behavior of the use of social media.

\section{References}

[1] R. Nasrullah, Media Sosial: Perspektif Komunikasi, Budaya, dan Sosioteknologi. Jakarta: Simbiosa Rekatama Media, 2015.

[2] K. Soeparno, K. \& L. Sandra, Social Psychology: The Passion of Psychology. Buletin Psikologi, vol. 19, no. 1, pp. 16-28, 2011.

[3] D. Laughey, Themes in Media Theory. New York: Open University Press, 2007.

[4] D. McQuail, Teori Komunikasi Massa. Jakarta: Penerbit Erlangga, 2003.

[5] C. Fuchs, Social Media a Critical Introduction. Los Angeles: SAGE Publication, Ltd, 2014.

[6] C. Fuchs, Internet and Society, Social Theory in the Information Age. New York: Roudledge, 2008.

[7] M.E. Shaw, \& P.R. Costanzo, Theories of Social Psychology. Tokyo: Kosaido Printing, 1982.

[8] S.W. Sarwono, Teori-teori Psikologi Sosial. Jakarta: Rajawali Press, 2013.

[9] R.A. Baron, \& D. Byrne, Social Psychology, New York: Pearson Education Inc, 2003. 
[10] B. Krahe, The Social Psychology of Aggression. Philadelphia: Psychology Press Ltd, 2005.

[11] D.R. Forsyth, Group Dynamic. Belmont: Cencage Learning, 2010.

[12] G. LeBon, G. The Crowd: A Study of the Popular Mind, New York: Dover Publications, Inc, 2002.

[13] D. Irmawati, D, Pemanfaatan E-Commerce dalam Dunia Bisnis. Jurnal Ilmiah Orasi Bisnis, vol. 2, pp. 12-15, 2011.

[14] D.G. Myers, Social Psychology. Boston: McGraw Hill Company, 2002.

[15] F. Hanurawan, F, Psikologi Sosial Terapan dan Masalah-masalah Perilaku Sosial. Malang: Fakultas Ilmu Pendidikan Universitas Negeri Malang, 2011.

[16] H.A.Schwartz, H. A, J.C. Eichstaedt, M.L. Kern, L. Dziurzynski, S.M. Ramones, M. Agrawal, Personality, Gender, and Age in the Language of Social Media: The Open-Vocabulary Approach. Journal of Personality and Social Psychology, vol. 3, pp. 10-20, 2013. 